\title{
A PREDAÇÃO, A RECIPROCIDADE E O CASO DAS GUIANAS
}

Peter Rivière

Este artigo se assemelha a um daqueles rios que os geógrafos, pareceme, denominam "dendríticos". São rios que correm para o interior das massas de terra, onde se perdem nos pântanos. Espero, no entanto, que existam pontos de interesse ao longo de seu curso, e que ao menos sua nascente, se não sua destinação, esteja bem definida. Tomando o artigo de Philippe Descola (1992), "Societies of Nature and the Nature of Society", pretendo examinar as idéias nele contidas com relação aos grupos nativos das Guianas. M ais precisamente, era isso o que eu pretendia fazer, mas quando comecei a examinar o tema a questão se mostrou mais complexa do que me havia feito prever a argumentação de Descola.

Iniciarei por resumir a argumentação de Descola; prosseguirei examinando alguns comentários feitos sobre o tema por Kaj Århem (1996), em seu artigo "The Cosmic Food Web". Em seguida, vou considerar os esquemas gerais da organização social guianesa e, com base nas idéias de Descola, formular hipóteses sobre o modo como os povos da região deveriam conceber suas relações com a natureza e com o exterior; utilizando principalmente o material sobre os Tirió, examinarei então a situação concreta. Em conclusão - e é aí que me vejo em um pântano - pergunto-me se é possível ti pificar sociedades tão nitidamente quanto pretende Descola.

\section{Delineando o problema}

O artigo de Descola apresenta-se como uma contribuição a um problema muito antigo que há muito tem desafiado a antropologia enquanto ciência comparativa: a questão do que deve ser comparado. As dificuldades aqui são imensas, mas uma das formas reconhecidas de enfrentá-las é, em vez de permanecer no plano das práticas individuais ou formas insti- 
tucionais, extrair, mediante a análise desses planos, os princípios que os ordenam. O que pode ser então comparado é o modo como estes últimos dão origem a diferentes práticas sociais. Diversos autores têm proposto, nessa tradição, diferentes princípios: Lévi-Strauss, a "reciprocidade"; Dumont, a "hierarquia"; Dumézil, as "funções tripartite". Descola focalizou algo que tem sido há séculos do interesse de filósofos, historiadores e cientistas naturais: a objetificação da natureza. Ele afirma que "os princípios de construção da realidade social devem ser buscados, primariamente, nas relações entre os seres humanos e seu meio ambiente natural" (Descola 1992:109). Sustenta, então, haver uma homologia entre a forma com que as pessoas tratam a natureza e a forma como se tratam entre si. Esta hipótese, prossegue, se fortaleceria se sociedades semel hantes em ecossistemas similares objetificassem a natureza de formas diferentes.

Considerando que Descola é um amazonista, não é surpreendente que se volte para a Amazônia a fim de examinar sua hipótese. $O$ autor sugere que a região oferece justamente essa oportunidade, por abrigar pessoas que vivem em um ambiente semelhante e o exploram de forma similar, mas que objetificam a sociedade e a natureza de maneiras distintas. Antes de prosseguir, no entanto, Descola considera necessário limpar o terreno, adotando a distinção entre o que ele denomina o sistema totêmico e o anímico. No primeiro, segundo Lévi-Strauss, as diferenças observáveis entre as espécies naturais são utilizadas como modelo para distinções internas à sociedade; em outras palavras, trata-se de um sistema metafórico. $\mathrm{O}$ animismo, por outro lado:

“[...] dota os seres naturais não apenas de disposições humanas - atribuindo-Ihes o status de pessoas com emoções humanas e, freqüentemente, com a habilidade de falar - como também de atributos sociais - uma hierarquia de posições, comportamentos baseados no parentesco, respeito a certas normas de conduta."

O autor continua:

\footnotetext{
“Os sistemas anímicos são uma inversão simétrica das classificações totêmicas: não exploram as relações diferenciais entre espécies naturais para conferir uma ordem conceitual à sociedade, mas utilizam as categorias elementares que estruturam a vida social para organizar, em termos conceituais, as relações entre seres humanos e espécies naturais" (Descola 1992:114, ênfases no original).
} 
Tendo introduzido a noção de sistema anímico, Descola observa que as A méricas contêm inúmeros desses sistemas, assim como diferentes combinações de animismo e totemismo. Em aparte, eu diria que, embora me agrade o presente propósito de tomar os sistemas anímicos como uma constante dada, valeria certamente a pena explorar as diferenças entre eles, bem como as conseqüências dessas diferenças. Da mesma forma, a fim de estabelecer um cenário para seu estudo, Descola, embora reconheça a existência de importantes variações locais, toma como uma constante o ecossistema geralmente similar da floresta tropical, assim como os meios de sua exploração pela população nativa. Além disso, nota a uniformidade da morfologia social em toda a região, caracterizada por pequenos grupos locais autônomos e idealmente auto-suficientes, em que o sexo e a idade aparecem como os principais critérios da divisão do trabalho, pela descendência cognática e por um ordenamento concêntrico do espaço em termos do qual o exterior é visto com hostilidade. Ao mesmo tempo, os sistemas anímicos amazônicos são concebidos como sistemas fechados, em cujo interior circulariam todos os elementos necessários para a manutenção e continuidade do cosmos. Qualquer ruptura nessa circulação ameaça o sistema, mas os meios utilizados para restabelecer o equilíbrio diferem "de acordo com as concepções dos princípios de identidade e diferença que regem as relações dos seres humanos entre si e com os animais" (Descola 1992:116). Para demonstrá-lo, Descola escolhe dois exemplos etnográficos - o dos Tukano Desana do noroeste amazônico e o dos povos jívaro do Alto A mazonas - e examina os meios através dos quais é restabelecido o equilíbrio rompido pela morte. No primeiro caso, o princípio é o da reciprocidade; no segundo, o da predação.

Entre os Desana, o sistema fechado envolve trocas entre as esferas social e natural, de modo a evitar a perda de energia. Na morte, a alma de um humano vai para os grandes depósitos subaquáticos onde o M estre dos A nimais mantém guardados seus protegidos. Um xamã empreende viagens regulares para negociar com ele a liberação dos animais, que são, então, caçados pelos membros da comunidade, os quais compensam o M estre com a alma de um humano morto. Em outras palavras, humanos são trocados por animais, estabelecendo-se assim uma equivalência entre eles. Princípio semel hante de reciprocidade ou mútua dependência pode ser observado nos arranjos matrimoniais, nos rituais e nas especializações artesanais. Descola conclui que: "à semelhança do sistema de relações com o mundo animal, o domínio social dos Tukano é inteiramente regido pela lógica da reciprocidade" (1992:118). Há, no entanto, uma 
nota de rodapé importante, na qual salienta que "a reciprocidade não impede a violência interna". O autor refere-se, em particular, ao rapto de mulheres, que vê como uma forma de reciprocidade negativa operando no interior do metassistema cósmico. Isso contrasta com o homicídio de um membro de tribo não aparentada, que reduz efetivamente o suprimento de energia cósmica desta última - ou seja, a predação, nesse caso, não é gerativa. O que não fica claro é o que ocorre quando o homicídio se dá no interior da tribo, como deve certamente acontecer, ou quando se capturam mulheres de uma tribo inteiramente não aparentada.

Entre os povos jívaro, a circulação de elementos não inclui seres naturais não humanos, e a morte de um ser humano deve ser compensada na esfera humana - nesse caso etnográfico, mediante a caça de cabeças. O J ívaro, ao se apossar de uma cabeça, captura uma "identidade que permitirá que sua parentela se perpetue sem incorrer nas obrigações de reciprocidade inerentes à aliança matrimonial" (Descola 1992:118). A vítima deve pertencer a um grupo que não seja sociologicamente nem muito próximo, nem muito distante, de forma que a identidade capturada seja similar, mas, também, diferente; concretamente, isso significa um J ívaro de outra tribo. Embora esse sistema seja direcionado para a exclusão da reciprocidade, na prática a lei da vingança dita que, mais cedo ou mais tarde, o pagamento negado acabe por ser arrancado. A guerra intratribal não envolve a captura de cabeças, e sim, o assassinato e o rapto de mulheres e crianças - um ato que garante uma esposa sem impor as obrigações da afinidade. Esquema semelhante aparece na caça, onde a relação entre caçador e presa é retratada como uma relação de afinidade cooperativa, na qual não se deve nem se paga compensação alguma. Descola resume a situação: "O rapto de identidades reais ou virtuais entre inimigos próximos ou distantes, e a incorporação de animais sob a capa da afinidade fictícia, expressam, em domínios diferentes, uma idêntica negação de reciprocidade nas trocas com os outros" (1992:120).

Descola repete a constatação de que, sob vários aspectos, os Tukano e os J ívaro são muito semelhantes entre si, na exploração do meio ambiente, nas suas tecnologias, na divisão do trabalho e na adesão a uma lógica característica dos sistemas anímicos. M esmo assim, as suas interações concretas com a natureza são baseadas em princípios fundamentalmente diferentes. Esses dois exemplos contrastantes de predação e reciprocidade não exaurem todas as formas que podem tomar os sistemas anímicos ameríndios, e Descola chama a atenção, brevemente, para o que denomina "dualismo ontológico" dos Aruak da região peruana subandina. 
A presentei o argumento de Descola quase com suas próprias palavras. Retornarei, mais adiante, ao que vejo como problemático na forma como o autor apresentou o caso jívaro. Aqui gostaria apenas de sublinhar que, no que toca ao noroeste amazônico, ele se baseia no Amazonian Cosmos, de Reichel-Dolmatoff (1971), cuja apresentação da cosmologia desana faz-nos pensar estar ouvindo um físico ocidental. O relato de Århem sobre a cosmologia makuna não é muito diferente, a não ser pelo fato de ser apresentado em termos muito mais próximos das idéias nativas do que da nossa física. Os Tukano falam de predação, não de transferência de energia. Århem dá também um rumo algo diferente ao argumento de Descola. Sustenta que a predação é lugar-comum no mundo makuna e que, de fato, todo seu universo é ordenado por uma série de relações na forma "predador/presa". Cito:

"A categoria suprema dos predadores, que compreende jaguares, anacondas e os principais rapaces, inclui também os deuses e os predatórios espíritos-he, transformando dessa maneira o sistema em uma verdadeira ecologia cósmica. Assim como o caçador humano mata e consome sua presa, os deuses matam e consomem humanos. Mas - e essa é a chave de todo o sistema - através da morte e consumo de seres humanos os deuses permitem que os homens se reproduzam. A nalogamente, mediante a predação da caça e do peixe, o caçador humano possibilita que os animais cresçam e se multipliquem. A predação, pois, é um ‘modelo' masculino de procriação”. (Århem 1996:189)

Dessa forma, aponta o autor, matar por comida é um ato de reciprocidade - a vida do indivíduo é trocada pela renovação da categoria, humana ou animal. E (cito novamente) "a predação, reconstruída como troca, explica a morte e dá conta da regeneração da vida". Na conclusão de seu artigo, Århem observa que

“[...] os temas da predação e reciprocidade, vingança e renovação, permeiam as cosmologias amazônicas [...]. Embora variando em forma e expressão, as representações locais do relacionamento humano-natureza na Amazônia parecem ser transformações de um padrão fundamentalmente similar, característico da região como um todo" (1996:201)1.

Há uma nota a esta citação na qual Århem sugere que os casos tukano e jívaro seriam muito mais próximos do que parecem no estudo de Descola. Embora eu concorde basicamente com esta avaliação, há um aspecto para o qual gostaria de chamar a atenção, pois penso existir uma 
diferença significativa entre os dois casos. Os dois grupos têm expectativas diferenciadas no que diz respeito à residência pós-marital: uxorilocalidade no caso jívaro e virilocalidade no caso tukano. $\mathrm{Na}$ realidade, as coisas não se dão exatamente assim, e retornarei em breve a este ponto, mas a composição efetiva dos assentamentos é confusa demais para ser analisada aqui, e por isso vou ater-me ao plano dos ideais e das expectativas. Os que conhecem meu trabalho sabem que penso que a residência pós-marital é uma variável importante naquilo que Eduardo Viveiros de Castro (1996a) designou como a "economia política do controle" nas terras baixas sul-americanas. Em resumo, postulo que as pessoas são muito valorizadas - principalmente as mulheres solteiras em idade de procriar - porque representam um recurso escasso. A uxorilocalidade é uma política muito mais cautelosa, voltada para dentro, do que a virilocalidade, que representa um potencial de desenvolvimento de alianças muito maior2. Destaco, aqui, essa questão, porque me parece relevante para tratarmos da situação da Guiana, o que me proponho a fazer agora.

\section{A situação nas Guianas}

A primeira coisa a salientar é o fato de que, em termos ecológicos amplos, o ecossistema das Guianas e aquele das áreas ocupadas pelos Tukano e pelos J ívaro são basicamente semelhantes. Também não diferem os sistemas de subsistência e as economias, e todos os povos da região compartiIham uma visão de mundo anímica. Existem também muitas similaridades no plano da morfologia social, incluindo o tamanho e distribuição das comunidades e os arranjos políticos. O interessante, no entanto, é que a semelhança seja maior quando se observa a organização e os sistemas concretos do que quando se considera as estruturas ideais. Pretendo proceder descrevendo as configurações ideais da estrutura social guianesa e observando, em seguida, o grau de convergência entre os arranjos concretos nas três regiões que nos interessam, antes de sublinhar o contraste existente no plano ideal.

Nas Guianas, os assentamentos não são apenas considerados politicamente autônomos e economicamente auto-suficientes, mas são também idealmente tomados como demograficamente auto-sustentáveis ou, em outras palavras, endogâmicos. A separação física e social do assentamento em relação ao mundo exterior é igualada por um confinamento também metafísico. Isto é vividamente retratado no caso dos Y e'kuana; entre eles, a cerimônia que acompanha a conclusão da casa inclui a reci- 
tação do nome de cada espírito e tribo estrangeiros, acompanhada da ordem para que permaneçam afastados. David Guss escreveu: "O círculo da casa é dessa maneira selado tanto física quanto simbolicamente, reforçando a autonomia e a auto-suficiência que constituem o ideal de toda comunidade ye'kuana" (1989:26).

Um aspecto disso, aqui como alhures na Amazônia, é o ordenamento concêntrico do espaço, segundo o qual o interior é associado à segurança e à familiaridade, e o exterior ao perigo e ao desconhecido, embora essas qualidades sejam mais contextuais e relativas do que absolutas. Os habitantes de um assentamento são concebidos como um grupo de consangüíneos, e uma conseqüência disto é a co-residência ser tão importante quanto o parentesco na ordenação dos relacionamentos.

Essa concepção de independência solitária, envolvendo a negação da reciprocidade, é um sonho seguramente utópico, já que, na prática, a auto-suficiência é ilusória, na medida em que os assentamentos dependem uns dos outros para a obtenção de bens materiais e de conhecimentos e práticas rituais, sendo ainda demograficamente muito diminutos para alimentar qualquer expectativa real ista de endogamia. Estatisticamente, o malogro do ideal de endogamia aldeã resulta em uma tendência uxorilocal que é, entre outras coisas, conseqüência de arranjos matrimoniais que colocam os jovens futuros maridos em desvantagem nas negociações com seus futuros sogros. Em outras palavras, o assentamento não se compõe, na prática, de uma parentela endogâmica, mas de um conjunto variável de relações no qual a uxorilocalidade é estatisticamente predominante. A unidade endogâmica constitui o que denominei "aglomerado" (Rivière 1969:37). Este é composto por diversas aldeias ligadas por uma densa rede de relações de parentesco e afinidade, elos que são relativamente raros para além das fronteiras do aglomerado. De modo geral, não existem termos nativos para designar esses agrupamentos sociais, embora desse ponto de vista os Piaroa constituam uma exceção na região. A crescente-se também que as relações entre assentamentos no interior de um mesmo aglomerado não são sempre um mar de rosas. Caracterizam-se por graus variáveis e mutantes de amizade e animosidade, dependendo dos acontecimentos. Além disso, os aglomerados não são hermeticamente fechados, e as suas fronteiras movem-se na medida em que as populações migram e os assentamentos se deslocam.

Voltemo-nos agora para a comparação entre a situação das Guianas e a dos Tukano. No plano ideal, há algumas diferenças muito óbvias, das quais a mais notável talvez seja a existência entre os Tukano de grupos de descendência patrilinear que praticam a exogamia e a residência viri- 
local. A relação quase hierárquica entre os vários grupos de descendência e um sistema regional de trocas acompanhado de um complexo ciclo ritual são traços que não encontram contrapartida nas Guianas. Por outro lado, se rasparmos a superfície dessa descrição ideal, encontraremos sob ela um quadro ligeiramente diferente. A maloca tukano, enquanto unidade social, oculta o fato de que o assentamento freqüentemente não se compõe apenas de um grupo de descendência patrilinear, mas de uma quantidade de consangüíneos e afins, incluindo genros prestando temporariamente o serviço-da-noiva. Os Tukano vivem em assentamentos que são parte de um conjunto de assentamentos ligados por uma densa rede de trocas matrimoniais e outras. Dessa forma, embora os assentamentos individuais sejam exogâmicos, o universo demográfico no interior do qual ocorre a maioria das trocas matrimoniais parece ser semeIhante, em tamanho, ao das Guianas.

Aqui, vale a pena lembrar a demonstração de Århem (1981) de que os arranjos matrimoniais makuna se inserem no modelo das esferas de reciprocidade de Sahlins: no interior do universo onde se dá a maioria dos casamentos, a reciprocidade matrimonial é de natureza generalizada, enquanto as uniões com pessoas exteriores a esse universo são caracterizadas pela reciprocidade balanceada, e aquelas com parceiros ainda mais distantes pela reciprocidade negativa (ou casamento por captura). Esta última forma só é viável no caso de povos cuja distância torne difíceis quaisquer tentativas de resgate ou fuga da noiva. Uma das alegadas vantagens desse tipo de casamento está em que o homem não tem de retribuir a esposa adquirida com uma mulher de seu próprio grupo, e fica livre das obrigações decorrentes da afinidade. Isto soa bastante jívaro, e embora o rapto de mulheres não seja desconhecido nas Guianas (os Yanomami não estão sendo considerados), há aqui uma outra forma de evitar os dissabores do serviço-da-noiva. A estratégia para evitar as obrigações da afinidade é, não roubar uma mulher distante, mas casar-se com uma o mais proximamente aparentada possível.

Se agora considerarmos os J ívaro, verificamos que, nesses termos, eles não são tão diferentes dos outros dois grupos. Descola observou a existência de grupos sociais supralocais para os quais os Shuar não dispõem de designação e que ele denominou "nexus endogâmico" (1994:9). Esses nexus são obviamente muito similares aos agrupamentos encontrados no noroeste amazônico e nas Guianas. A lém disso, embora ele descreva a residência como sendo "estritamente uxorilocal", é claro que a composição das casas não é assim tão bem regulada, e que o rapto de mulheres resulta, obviamente, em algum nível de virilocalidade. $O$ que 
parece diferenciar o caso jívaro dos Tukano e dos povos da Guiana é o extremo atomismo, o assentamento sendo aqui raramente constituído por mais de uma unidade doméstica - exceto nos períodos de hostilidade, quando várias dessas unidades se associam em uma única moradia fortificada, que pode conter sessenta ou setenta pessoas, por períodos de até mesmo quatro anos.

Minha preocupação até aqui foi mostrar que a região guianense corresponde às expectativas de Descola para sociedades que vivem em meio ambientes similares e os exploram de forma semelhante; e que a morfologia social das três áreas é também similar. Há contudo contrastes no plano das expectativas sociais. Temos uma sociedade idealmente uxorilocal, outra idealmente virilocal, e uma sociedade idealmente endogâmica do ponto de vista local. No primeiro caso, Descola caracteriza a relação com a natureza como baseada na predação; no segundo, na reciprocidade. Mas o que se deve esperar de uma sociedade endogâmica? Presumivelmente, o isolamento da natureza. Poder-se-ia formular a hipótese de que, no que toca à reprodução, a natureza é uma categoria redundante. Examinemos as evidências.

\section{Morte e reprodução}

Descola concentra seu trabalho na situação específica da morte e na substituição dos mortos; talvez então seja para isto que devamos inicialmente nos voltar no contexto guianês. Como os Tukano e os J ívaro, os povos das Guianas vêem sua cosmologia como fechada e finita; deveria haver, portanto, um problema quanto à substituição de pessoas que poderiam, de outro modo, perder-se para o sistema. Não está claro se este problema realmente se coloca; o que se sabe, é que esses povos não adotaram nada semelhante às soluções tukano ou jívaro. Há alguma evidência, entre os Waiwai, quanto à circulação de matéria espiritual entre este e o outro mundo, envolvendo um sistema de reciprocidade que inclui o $M$ estre dos Animais de Caça, mas não se trata de uma noção bem desenvolvida (M orton 1979). Em todos os outros casos, a idéia de que a morte envolve reciprocidade entre os dois mundos - ou seja, reciprocidade como modo de regeneração, disfarçada ou não de predação - parece ausente. De fato, em um certo sentido, pode-se argumentar que, para alguns povos nas Guianas, a morte não existe, ou melhor, não passa de uma ilusão. Como o nascimento, consiste apenas em uma passagem entre dois modos de ser. Permitam-me citar Guss a respeito dos Ye'kuana: 
“A morte aqui, entretanto, não é um simples estado de não-ser, que torna absurdos todos os esforços de vida, mas a energia bruta através da qual o próprio ser é criado. No mundo de Wanadi [o herói da cultura ye'kuana], assim como para aqueles que vivem à sua imagem [os ye'kuana], não há estado de não-ser. Há apenas o presente eterno, o mundo do duplo invisível que segue vivendo para sempre, mesmo após o desaparecimento da forma material. O que parece como real é apenas uma ilusão. [...] A morte, portanto, mais do que um término, é um ingresso na realidade" (1989:119).

Não há, no caso ye'kuana, sugestão de que ocorra um retorno, mas sim transferência para um plano mais "real" de existência. Permanece obscuro de onde vem a nova vida, embora não possamos deixar de nos impressionar com o fato de que o herói cultural Wanadi deu a luz a si mesmo - a forma máxima de auto-suficiência.

M ais dois exemplos: o missionário alemão (que se tornou antropólogo brasileiro) Protásio Frikel (1971) relatou que, para os Kachuyana, a morte é o nascimento em outra vida, e o nascimento a reencarnação na terra, sem que haja, aparentemente, a intervenção de qualquer outra agência. Entre os Tirió, existe a idéia de que, no momento da morte, a alma parte para uma viagem arriscada em direção ao reservatório de almas, no horizonte oriental, de onde é retirada a matéria espiritual para o recém-nascido. Verifica-se, nesses exemplos, que os sistemas em questão são autosuficientes e não dependem da interação, recíproca ou predatória, com terceiros. Essas idéias são inteiramente consistentes com a visão ideal do assentamento enquanto unidade produtiva e reprodutiva auto-suficiente.

Aqui, parece-me interessante acrescentar uma nova dimensão. Venho discutindo o que acontece na morte porque esse é o enfoque de Descola, mas vale a pena também considerar o que causa a morte. Esta resulta, na maior parte das Guianas, de ataque místico, feitiçaria, roubo de alma e similares, provenientes sempre do exterior, seja seu causador um humano ou um espírito, embora no último caso se suspeite geralmente da presença de uma agência humana encoberta. Da mesma forma, a feitiçaria de vingança é sempre dirigida para fora. Em outras palavras, no que diz respeito à causa da morte, a relação entre interior e exterior é expressa em termos de predação, podendo-se então sustentar com segurança que, dessa forma, se ajuda a delimitar a comunidade, uma vez que a feitiçaria, por definição, não pode ocorrer dentro desta última.

A causa da morte entre os J ívaro é tratada somente de passagem; em meu rápido sobrevôo, pelo menos, não encontrei um tratamento mais completo desse tópico. Anne-Christine Taylor (1993:662) afirma que a 
morte resulta de intenção humana maligna, seja física ou mística. Descola (1994:125) refere-se aos dardos mágicos atirados pelos xamãs ou às doenças ocidentais, ao que se deve, provavelmente, acrescentar as mortes violentas. Todas essas causas se ajustam bem à visão de que os processos reprodutivos são confinados à esfera humana. Todavia, Descola menciona também o fato de que, entre crianças e velhos, a morte pode resultar da perda de sangue, e que enquanto para os últimos isso faria parte da deterioração geral da velhice, para os primeiros resulta das práticas vampíricas da mandioca. A penas para mostrar quão problemática é a interpretação dessa idéia, considere-se que a mandioca consiste, sem dúvida, em uma planta, mas, uma planta ao mesmo tempo altamente socializada, cujas raízes são tratadas pelo cultivador como crianças (Descola 1994:204-205). No sistema anímico, a consangüinidade da mandioca com o cultivador faz dela a parte mais humana da natureza, mas ela também parece ser a parte que intervém no processo de vida e morte dos J ívaro. Suponho que seria preciso argumentar aqui que, se os processos de predação ocorrem inteiramente dentro da esfera humana, isso seria de se esperar.

Os casos das Guianas e dos J ívaro contrastam com o dos Tukano, que, conforme observado, atribuem a morte à esfera não humana. Dessa forma, para os M akuna, cada humano é definitivamente morto e consumido pelos deuses como parte do ciclo de transferência entre diferentes esferas cósmicas.

Entretanto, no caso das Guianas, se deixarmos a morte de lado para observar outros eventos em que o mundo exterior é um fator crucial, encontramos um quadro bastante diferente; a saber, um quadro que envolve reciprocidade, e é claramente marcado pela interdependência. Estou me referindo a essas ocasiões - certos eventos rituais vitais - cujo sucesso demanda a interferência de pessoas de fora. Incluem, por exemplo, os ritos de iniciação panare e waiyana e os rituais waiwai de conclusão da casa - todos episódios cruciais para a reprodução social que reconhecem de forma bastante explícita a impossibilidade de uma total autosuficiência. Em termos de um funcionalismo tosco, a necessidade de participação externa nesses ritos rompe o isolamento perigoso dos assentamentos e gera intercâmbio entre eles, o que, no entanto, dificilmente constitui uma explicação: trata-se, na melhor das hipóteses, de uma função latente. Outro argumento seria que esses episódios constituem apenas mais alguns exemplos da fusão do semelhante com o dessemelhante, apontada por J oanna Overing (Overing Kaplan 1981) há duas décadas como um pré-requisito essencial da criatividade nas terras baixas sul- 
americanas. Certos tipos de criatividade dependem da mistura de dessemelhantes, dos quais interior e exterior constituem a forma estereotipa$\mathrm{da}$, e isto se torna mais claro nos momentos essenciais de reprodução social - a criação de seres humanos na iniciação e de unidades sociais na casa. Penso, no entanto, que há ainda um adendo a ser acrescentado a isso: para atingir a unidade cósmica, o que a criatividade exige é a transcendência dos semelhantes e dessemel hantes mundanos. $\mathrm{N}$ ão se trata simplesmente de a transcendência ser alcançada através do ritual, mas sim de o próprio tempo ritual ser transcendência. É a transcendência temporária, durante a qual as divisões do mundo comum são suprimidas, que constitui a criatividade, e não apenas as diferenças em si. Isso é bem documentado para o caso tukano: durante o ritual da casa-He, principal rito de iniciação, tempo e espaço se fundem como no momento primordial (Hugh-J ones 1977). O que desejo sublinhar aqui é algo bastante paradoxal: a dependência diante do mundo exterior para a reprodução do mundo do sujeito é negada pelo expediente de supressão desse mundo exterior e pela criação ritual de um único cosmos transcendente.

Embora a importância da participação de forasteiros como convidados seja amplamente documentada nos rituais guianeses e tukano, este não é o caso, curiosamente, dos povos jívaro. De fato, Descola (1996, cap. 24) descreve apenas dois eventos: o anemat, "um dos raros ritos coletivos que essa sociedade individualista inventou para si mesma" (Descola 1996:390), realizado com a finalidade de reunir um grupo de guerreiros como prelúdio para os ataques; e o ujai, realizado pelas mulheres quando os homens se ausentam para a guerra. Em outras palavras, os ritos coletivos são associados, aqui, à ação predatória sobre o mundo exterior, e não à dependência recíproca entre este e o interior.

\section{Relações com a natureza na mitologia Tirió}

Parece-me oportuno examinar, agora, a relação dos Tirió com a natureza, conforme retratada em sua mitologia. Resumindo, para começar, proponho considerar aquilo que, na falta de melhor designação, poderia ser dito seu mito de origem da cultura (M ito 1$)^{3}$. Neste, o herói cultural recebe do Mestre do M undo Aquático Subterrâneo, que pode ser um crocodilo ou uma anaconda gigantes, não apenas uma esposa mas também uma vasta gama de conhecimentos e objetos culturais: a casa, o fogo, a agricultura, as plantas cultivadas, a cozinha etc. O que é notável a respeito desse mito, amplamente conhecido e do qual ouvi diversas varian- 
tes, é que o herói cultural não oferece nada em troca do que recebe. Em outras palavras, a relação com a natureza, ou, como prefiro, com o Outro, é de mão única, mas não parece ser predatória. Não somente a esposa, que é pescada da água e não se mostra infeliz com isso, mas todos os bens são oferecidos e não simplesmente tomados. Seria difícil considerar esta uma relação predatória, embora ela seja certamente unidirecional. Vamos examinar como a mitologia trata as relações dos Tirió com os animais, tomando três mitos em que essas relações são retratadas.

Todos os três mitos se referem a encontros dos Tirió com animais de caça: anta (Mito 14), macaco-aranha (M ito 16) e queixada (M ito 17). Os dois primeiros são muito semelhantes, e podem ser tratados mais ou menos em paralelo. Nos dois casos, as pessoas haviam ouvido falar desses animais, sem nunca tê-los encontrado, embora houvessem tentado. A mbos os heróis são xamãs que, tendo ido sozinhos à floresta, encontram-se acidentalmente com Anta, em um caso, e com M acaco-aranha, no outro, os quais se dirigem ao xamã chamando-o de neto, sendo por este tratados de "avô", um termo de respeito. Neste ponto há uma diferença: o xamã que encontra $\mathrm{M}$ acaco-aranha está se preparando para atirar no animal quando este o percebe e o adverte de que nada de bom Ihe acontecerá se o matar. Os xamãs são convidados pelos animais a suas respectivas aldeias, onde são recebidos e, como já é tarde, chamados a passar a noite. Aqui aparece uma pequena divergência entre os dois mitos: o xamã que está na casa de Anta deve dividir sua rede com a filha deste, a quem tenta seduzir, mas é impedido pela vigilância do pai. O xamã não consegue compreender por que fora convidado a compartilhar a rede com a filha do anfitrião se esta não pode ser tocada. No dia seguinte, o Tirió deseja partir, mas é retido por Anta, que quer Ihe falar de seus planos para banhar-se (uma referência, presumo, ao hábito das antas de quando assustadas buscar refúgio na água - e, portanto, à transmissão de um segredo) ${ }^{4}$. Finalmente, o homem consegue partir, tendo sido advertido para que não contasse a ninguém onde ele - Anta - morava; se o fizesse, algum mal Ihe sobreviria.

O xamã que se encontrou com M acaco-aranha é alojado sozinho em uma rede, mas, porque a aldeia de seu anfitrião fica no alto da árvore, é advertido sobre não urinar durante a noite. Ele sente, no entanto, necessidade de fazê-lo, e ignora a advertência, sendo, no último momento, salvo de cair de um galho por M acaco-aranha. Ao amanhecer, o xamã ouve os gritos de vários tipos de macacos, que são para ele identificados por seu anfitrião - outro exemplo de transmissão de conhecimento. Como no outro caso, quando, de manhã, o Tirió está prestes a sair, dizem-Ihe 
também para não mencionar M acaco-aranha para seus conhecidos; do contrário, avisam-no, uma desgraça iria Ihe acontecer.

O episódio seguinte é semelhante nos dois mitos. Quando os xamãs chegam em casa, seus cunhados insistem em saber por que passaram a noite fora e onde, mas eles nada dizem. Em ambos os casos, o segredo é revelado por línguas soltas em conseqüência do consumo de bebida forte. Na história do homem que encontrou Anta, a bebida Ihe é dada diretamente e, sob o seu efeito, ele conta o ocorrido para a mulher que, por sua vez, passa a informação para seus irmãos. $\mathrm{Na}$ outra história, a bebida é dada para a esposa do homem que encontrou Macaco-aranha, a qual revela o segredo do marido para os irmãos, embora, no mito, não fique claro em que ponto e sob que condições ela tomara conhecimento do acontecido. O mito de Macaco-aranha conclui-se, então, bruscamente. Os homens saem à procura do animal, levando consigo o xamã. Este se oferece para ir encontrá-lo sozinho, mas é seguido pelos cunhados, que matam a mulher e a filha de Macaco-aranha. $\mathrm{O}$ xamã foge, mas é perseguido e morto por este último.

O mito de Anta tem um final mais elaborado. O xamã, por causa da ameaça, diz a seus cunhados que, caso queiram encontrar Anta, deverão procurá-lo por si mesmos, mas aqueles continuam a perturbá-lo até que ele se rende. Mais uma vez, ao aproximarem-se da aldeia do animal, o xamã pede para prosseguir sozinho, mas os cunhados soltam seus cães de caça, que matam a mulher e a filha de Anta. Anta, então, caça e mata o xamã. Segue-se mais um episódio, no qual a mulher do último persuade seus irmãos a vingar o marido. Um dos irmãos, outro xamã, será auxiliado na realização da tarefa por seu espírito familiar, Esquilo, mas Anta escapa, apesar da armadilha montada com comida para ele. Seu destino será finalmente selado em um incidente curioso: durante uma sessão xamânica, Anta não consegue reconhecer que os objetos naturais que Ihe são mostrados constituem as partes componentes de uma flecha. Em conseqüência, torna-se vulnerável. Este último episódio do mito confirma a animalidade de Anta, que não é capaz de reconhecer nos materiais naturais o potencial para um objeto cultural.

As características dos mitos que quero enfatizar são as seguintes: os Tirió sabiam da existência de uma criatura na floresta, mas não tinham contato com ela. Um xamã encontra a criatura, que o recebe, oferecendo-Ihe alimento e abrigo. $\mathrm{N}$ os dois casos, o xamã chama o animal de "avô" - um termo de respeito. A hospitalidade de Anta não se estende a ponto de permitir ao xamã acesso à sua filha, enquanto $M$ acaco-aranha salva seu convidado. Os dois anfitriões oferecem, também, uma 
grande quantidade adicional de informações, mas advertem seus visitantes para manter tudo em segredo, ou serão mortos. Sob a influência da bebida, o segredo é revelado, levando à morte do xamã. O que é notável em ambos os casos é a falta de comunicação entre os dois lados. A história tem início sem que haja entre eles qualquer contato; por acaso, estabelece-se uma linha potencialmente profícua de comunicação, mas esta é fechada novamente devido à exigência, tanto de Anta quanto de M acaco-aranha, de que a sua presença seja mantida em segredo. A falha em manter o segredo abre caminho para incursões predatórias que resultam em mortes dos dois lados. A natureza da relação entre o interior e o exterior é baseada em traição e engodo, e falha em estabelecer um modus vivendi entre as partes. Isto fica bem explícito quando consideramos o terceiro mito, bastante diferente dos outros - o do encontro com o queixada.

Este mito principia de forma muito semelhante aos outros dois. Antigamente, não havia queixadas nas redondezas, e os Tirió, embora tivessem conhecimento de sua existência, não podiam encontrá-los. De fato, naquela época, nenhum dos animais de caça preferidos estava disponível, e os que existiam eram pouco apetitosos (tamanduá) ou considerados ridículos enquanto comida (beija-flor). Um xamã foi persuadido a sair em busca de queixadas, mas antes de partir exigiu que o chefe da aldeia Ihe garantisse que aquele, se encontrado, seria bem tratado. $O$ xamã exige que o filho do chefe o acompanhe, e que Ihe seja fornecida comida para o que prevê ser uma longa viagem. O xamã e o jovem partem, e encontram o caminho bloqueado por uma série de obstáculos; atravessam um vasto rio, e então a trilha desaparece em uma abertura no solo. (Esta é a forma tradicional com que os Tirió descrevem a entrada para o nível cósmico subterrâneo.) Alcançam, então, outro grande rio, após o que enfrentam vários ordálios, impostos por tartarugas gigantes, cobras e jaguares. Vencem esses perigos e chegam a um brejo de palmeiras, onde se encontra a aldeia dos queixadas. O xamã e o jovem vestem-se como para uma dança, e encontram um queixada, que aparece sob a forma de um homem. Curiosamente, o xamã dirige-se imediatamente a ele como "parceiro comercial", e lhe pede que os conduza ao M estre dos Queixadas. Os Tirió são levados à aldeia, onde há muita gente reunida, bebendo, comendo e rindo. São, então, cumprimentados pelas pessoas que, apesar de sua aparência humana, exibem uma característica porcina, golpeando os visitantes com suas cabeças.

A primeira troca entre o xamã e o M estre dos Queixadas é muito instrutiva. O primeiro dirige-se ao segundo respeitosamente como "avô"; o 
segundo, por sua vez, diz: "não me chame assim porque você é meu parceiro comercial e, portanto, deve me chamar 'amigo'" (ipawana). O xamã explica então ao M estre dos Queixadas por que vieram: querem seus seguidores, isto é, os queixadas. A conversação, com ambas as partes expondo enfaticamente seus motivos, continua por muito tempo - dia e noite talvez por dez dias. Isto faz com que eles pareçam envolvidos em um diálogo cerimonial, a linguagem formal de negociação, embora curiosamente somente mais adiante, no mesmo mito, se afirme explicitamente que o diálogo cerimonial foi usado pela primeira vez e ensinado aos Tirió pelos queixadas (Rivière 1971). Eles permitem que o M estre dos Queixadas experimente a comida que haviam trazido, prometendo-Ihe que esta estaria disponível para seus seguidores quando fossem visitar os Tirió. 0 M estre é prudente, e avisa que os queixadas fazem uma grande bagunça ao comer (isto é, fazem grandes estragos nas hortas), mas o xamã afirma que, prevenido, aceitará o risco. Fica combinado que os queixadas irão no momento devido, mas que a comida deverá ser deixada ao longo do caminho para eles. Depois disso, os dois Tirió voltam para casa, e mandam colocar a comida na trilha. No final da estação das chuvas, os queixadas aparecem, e a descrição feita é muito semelhante à da chegada de uma comitiva de visitantes humanos, sendo nessa ocasião que os Tirió ouvem o diálogo cerimonial pela primeira vez. Fecham aparentemente um acordo, em que os Tirió se comprometem a tratar bem os queixadas, e a matar apenas uns poucos de cada vez.

O final do mito não é inteiramente feliz. Os queixadas multiplicamse, mas não sob a forma em que foram primeiro conhecidos. Isto porque, tendo um xamã violentado a filha do M estre dos Queixadas, este decide, em conseqüência, transformar seus seguidores em lagartas, e a carne de queixada que os Tirió comem atualmente não é nem de longe tão boa quanto fora no passado. Este é um motivo típico da mitologia Tirió, que remete a uma idade de ouro quando tudo era melhor do que agora e podia ser obtido com muito menos esforço. Essa idade de ouro é invariavelmente perdida em virtude de alguma ação perversa ou desastrada cometida por um Tirió. Pode-se observar também que esse mito guarda muitas similaridades com as idéias tukano - a diferença vital é que aqui se dá comida em troca dos queixadas, e não almas humanas.

O contraste dessa terceira história com as outras duas é notável. Os Tirió partem com o objetivo explícito de encontrar os queixadas, em vez de apenas se depararem com eles acidentalmente. A viagem é muito longa e eles levam comida que oferecem aos queixadas. É dito claramente que os Tirió e os queixadas serão parceiros comerciais - uma relação 
entre iguais que envolve reciprocidade equilibrada e, freqüentemente, protelada; ou seja, uma relação baseada na confiança. Os termos dessa troca são alimentos cultivados e respeito, de um lado, e um suprimento moderado de caça, de outro. Aqui temos evidências claras de uma reciprocidade negociada entre as sociedades humana e animal, em oposição ao mal ogro em estabelecer qualquer relação duradoura observado nas histórias de Macaco-aranha e de Anta.

A questão que imediatamente se coloca é a da determinação da diferença entre o queixada, de um lado, e a anta e/ou macaco-aranha, de outro. A resposta mais óbvia e imediata é que os queixadas são retratados como levando uma vida muito sociável; há muitos deles na aldeia, comendo e bebendo juntos, e todos têm a aparência de pessoas. Em contraste, tanto Anta quanto $\mathrm{M}$ acaco-aranha vivem apenas com mulher $\mathrm{e}$ filha(s), e não há nenhum indício de que sejam qualquer outra coisa senão animais. É verdade que, na natureza, os macacos-aranha vivem certamente em grandes bandos, e as antas, embora menos gregárias, não são solitárias; mas os Tirió - como é, em geral, o caso na Amazônia - vêem o queixada como um animal particularmente sociável. Em outras palavras, em um continuum de socialização, os queixadas são mais socializados (ou humanizados) do que as antas e os macacos-aranha, sendo, portanto, possível estabelecer um tipo de relação diferente com eles - uma relação de negociação em lugar de predação ou falta de comunicação. Esta afirmação é sustentada por outra diferença importante. Esta consiste em que os animais protagonistas nos dois primeiros mitos parecem ser apenas animais (se é que se pode alguma vez afirmar isto no contexto amazônico), enquanto no terceiro, fica claro que o personagem significante não é o queixada, mas o M estre dos Queixadas - um espírito bem diferenciado dos queixadas. Em outras palavras, nos dois primeiros casos estamos diante de uma comunicação direta com o mundo natural, enquanto no terceiro a relação é mediada pelo mundo sobrenatural. Maior sustentação para esta interpretação pode ser encontrada em um detal he do mito do macaco-aranha, onde se nota que, quando o xamã sobe na árvore com M acaco-aranha para acompanhá-lo à sua aldeia, o faz com seu próprio corpo. Isto é uma forma de dizer que ele não estava fazendo uma viagem xamânica. Tampouco há qualquer indício de que as coisas ocorram diferentemente no caso da visita à Anta. Por outro lado, o relato da viagem à aldeia dos queixadas, com todos os seus ordálios, guarda muitas semelhanças com a viagem da alma para seu local de descanso. Isso parece indicar uma jornada xamânica, na qual o xamã cumpre seu papel de psychopompós, e embora isto não seja diretamente explici- 
tado, há diversas outras pistas que sustentam essa interpretação, como, por exemplo, o caminho que leva ao subsolo.

Pergunto-me quanto a diferença de resultados entre os eventos - predação e vingança, de um lado, escambo e reciprocidade, de outro - não corresponderia à diferença entre tratar diretamente com os animais e tratar com o seu dono. Não tenho a resposta para isto, mas vale a pena examinar alguns outros aspectos que demonstram não serem as relações entre os Tirió e o mundo dos espíritos de modo algum sempre benignas, conforme indicam os dois mitos seguintes ( $M$ itos 49 e 50). Estes não envolvem humanos e animais, ou mestres de animais, mas humanos e espíritos. Aqui, o cenário é um tanto diferente. Os dois relatos tratam de xamãs diretamente envolvidos na morte de um parente, que então visitam a aldeia dos espíritos, onde estes últimos fazem entrar o morto amarrado como se fosse caça. Em ambos os casos o xamã se faz acompanhar de um não-xamã que, diferentemente dele, não se transforma para visitar o mundo dos espíritos. Nesse mundo, o xamã une-se aos espíritos para comer o morto, a quem vê, também, como caça.

Embora eu não queira divagar, podemos reconhecer aqui um exemplo do perspectivismo de Eduardo Viveiros de Castro (1996b), na medida em que o não-xamã, não transformado, vê o falecido como uma pessoa morta, enquanto os espíritos, e o xamã perverso, vêem o cadáver como sendo de um animal de caça. Nos dois casos, a vingança cabe ao Tirió sobrevivente e a seus parentes, resultando na morte do xamã perverso e de muitos espíritos. A pesar das complexidades adicionais referentes à participação humana nos eventos, fica muito claro que o tema subjacente a essas histórias é o da predação do mundo dos humanos pelo mundo dos espíritos: os espíritos vêem os humanos como caça a ser morta e levada para suas aldeias como alimento. Para vingar-se, os Tirió matam os espíritos e os xamãs perversos. Em outras palavras, as relações com a natureza e o sobrenatural tomam para os Tirió uma variedade de formas, paralelas à sua experiência social. Conforme observado anteriormente, as relações reais entre os assentamentos tendem a oscilar entre amizade e animosidade. Em aparte, eu poderia também acrescentar que os Tirió vêem os espíritos com considerável ambivalência, nunca se sentindo seguros quanto ao resultado da interação com eles. Contudo, mesmo se esta relação é conflitiva, não há sugestão de que a predação seja um aspecto da regeneração. A predação não opera como força motriz ou regeneradora do cosmos.

Poderíamos concluir ser essa afirmação igualmente verdadeira no caso dos J ívaro. No artigo que inspira este texto, o tratamento dado por 
Descola à interação dos J ívaro com o mundo dos espíritos omite muito do que ele nos conta em outros trabal hos. Ele observa que a reprodução humana envolve exclusivamente trocas predatórias na esfera dos humanos, e que as relações com animais são similares. As Mães da Caça são, através do uso de afinidade fictícia e enganosa, persuadidas a ceder os animais, sem, no entanto, nada receberem em troca. Todavia, na realidade, a relação com as $M$ ães da Caça é mais complexa, como o autor deixa claro alhures. As M ães da Caça impõem sanções aos caçadores que, por matarem em excesso ou por zombarem delas, desrespeitam sua relação com os animais. Além disso, há também a relação entre as mulheres e Nunkui, o espírito tutelar das hortas. Essa relação deveria ser direta, harmoniosa e de constante interação (Descola 1994:192). Não disponho de tempo para avançar mais, fico, no entanto, com a forte impressão de que as relações dos A chuar com o mundo natural/sobrenatural contêm mais aspectos do que aqueles facilmente acomodáveis sob a rubrica da "predação".

\section{Conclusão}

Adverti no início de que este artigo não se encaminhava para um final conclusivo. Se eu fosse obrigado a apresentar um, acho que diria ser possível mostrar que a afirmação de Descola, de que "há uma homologia entre o modo como as pessoas lidam com a natureza e o modo como tratam umas às outras", tem al guma validade, mas apenas no âmbito de determinadas evidências e dentro de certos contextos. Outras evidências negam essa homologia, ou talvez indiquem uma homologia diferente. Reduzir as relações da sociedade, seja no seu interior, seja com a natureza e o exterior, a um único modo, é provavel mente por demais reducionista. Certamente, não posso fazê-lo no que toca aos Tirió; no entanto, se examinarmos uma variedade de modos, cada um adequado a seu contexto, é possível, então, ver claramente que al gumas relações entre humanos são homólogas àquelas entre seres humanos e não humanos.

O problema, acredito, consiste no fato de que reciprocidade e predação têm sido consideradas formas radicalmente diferentes de interação, quando na realidade estão dispostas ao longo do mesmo espectro, diferindo não na forma mas no seu conteúdo e contexto. Não me parece surpreendente que Descola, em algumas ocasiões, fale em reciprocidade negativa, em lugar de predação, enquanto Århem se satisfaz em ver a predação como uma forma de reciprocidade. Tampouco me surpreende que Århem utilize o modelo de Sahlins. De fato, sempre pensei ("sem- 
pre" porque o disse em uma resenha de seu trabalho em 1966) que as esferas de reciprocidade de Sahlins - generalizadas, equilibradas e negativas - são um modelo que, se aplicado flexível e contextualmente (com o que quero dizer ser necessário considerar que as fronteiras entre esferas estão em constante movimento, ou melhor, renegociação), é bem adequado à situação amazônica. Devemos lembrar que o próprio Sahlins tinha plena consciência da instabilidade dessas esferas, tendo observado, argutamente, que a reciprocidade equilibrada era, provavelmente, a forma mais instável, tendendo a transformar-se em uma das outras. Esses modos de interação constituem traços variáveis de todas as sociedades amazônicas, sendo perfeitamente possível prever que determinado grupo seja mais fortemente caracterizado por um dos modos que por outros, mas é improvável que os exclua completamente5.

Recebido em 20 de novembro de 2000

A provado em 15 de janeiro de 2001

Tradução: Diana Antonaz

Revisão técnica: Yonne Leite e Marcela Coelho de Souza

Peter Rivière é professor-titular de A ntropologia Social da Universidade de Oxford e Fellow of the Linacre College, Inglaterra. É autor, entre outras publicações, de M arriage among the Trio (1969) e Individual and Society in Guiana (1984). 


\section{Notas}

1 Pode-se dizer que a visão judaico-cristã de vingança como reciprocidade equilibrada - a noção de olho por olho - não opera necessariamente no contexto sul-americano; e nem, suspeito, na prática, entre os povos judaico-cristãos. A vingança é incapaz de compensar inteiramente a perda, porque o que a pessoa perdeu é mais valioso que aquilo de que privou o outro. Nas trocas matrimoniais, a mulher que eu entrego nunca é completamente paga pela que recebo em troca; e o mesmo no homicídio. O membro de meu grupo, morto por você, não é substituído pelo membro do seu grupo, morto por mim, e vice-versa. A vingança nunca acerta as contas; o ciclo de violência, física ou mística, nunca se fecha. E nem poderia, é claro, se é ele afinal o moto-contínuo que impulsiona o cosmos. A vingança tem sido freqüentemente apontada como uma força motriz nas sociedades sul-americanas, e pode envolver retribuição tanto física quanto mística, embora uma tal distinção possa não ser feita pelas pessoas envolvidas.

2 Nisso, as duas práticas partilham características com a troca direta e a troca generalizada, respectivamente, mas não é minha intenção entrar nesse terreno.

3 Todos os mitos a seguir, e a sua numeração, são reproduzidos de Koelewijn e Rivière (1987).

4 A té então, nada se sabia sobre as antas, e o fato de que estas quando assustadas buscam abrigo nos rios consiste em um saber importante. Uma grande proporção das antas caçadas é morta nos rios, porque é mais fácil pegá-las ali.

5 Em abril de 1999, mandei uma cópia de um esboço anterior deste artigo para Philippe Descola, que assim respondeu em 13 de maio: “Admito de pronto que nenhuma sociedade na A mazônia ou em qualquer outro lugar possa organizar a sua prática de acordo com um único código diretor, seja esse a reciprocidade, a predação ou qualquer outra coisa. Por exemplo, os J ívaro são surpreendentemente recíprocos nas suas alianças de casamento, enquanto os Tukano, conforme mostra Kaj [Århem], têm, em certa medida, predação, como na captura da noiva e nas relações canibalísticas com certos elementos do cosmos. Poder-se-ia dizer que, enquanto valor dominante, a predação engloba a reciprocidade entre os J ívaro, enquanto o contrário é verdadeiro para os Tukano. A situação é mais complexa entre os Tirió e nas Guianas. Parece-me que estão mais próximos dos Arawak subandinos, uma vez que combinam uma obsessão pelo isolamento e a supressão da distância social dentro do grupo endogâmico, com uma relação com a natureza muito próxima das que vigoram com forasteiros, isto é, relações comerciais, de barganha etc. Dito isto, e apesar de minha grande admiração por Sahlins, sempre tive dificuldade em entender o significado de reciprocidade negativa. Por isso, a minha escolha recai sobre 'predação' - para escapar da tendência de universalizar a reciprocidade". 


\section{Referências bibliográficas}

ÅRHEM, K. 1981. Makuna Social Organization. A Study in Descent, Alliance and the Formation of Corporate Groups in the North-Western Amazon. Uppsala: Uppsala Studies in Cultural Anthropology 4.

.1996. "The Cosmic Food Web. Human-Nature Relatedness in the Northwest Amazon". In: P. Descola e G. Pálsson (eds.), Nature and Society. Anthropological Perspectives. London: Routledge. pp. 185-203.

DESCOLA, P. 1992. "Societies of Nature and the Nature of Society". In: A. Kuper (ed.), Conceptualizing Society. London/New York: Routledge. pp. 107-126.

.1994. In the Society of Nature.

A Native Ecology in Amazonia. Cambridge: Cambridge University Press.

. 1996. The Spears of Twilight. Life and Death in the A mazon J ungle. London: HarperCollins Publishers.

FRIKEL, P. 1971. “A M itologia Solar e a Filosofia de Vida dos Índios Kaxúyana". Estudos sobre Línguas e Culturas Indígenas (edição especial). Brasília: Summer Institute of Linguistics. pp. 103-142.

GUSS, D. 1989. To Weave and Sing. Art, Symbol, and Narrative in the South American Rain Forest. Berkeley/Los Angeles/London: California of University Press.

HUGH-J ONES, S. 1977. “Like Leaves on the Forest Floor: Ritual and Social Structure amongst the Barasana". Proceedings of the Forty-second Internal Congress of Americanists, 2:205-215. Paris.

KOELEWIJ N, C. e RIVIÈRE, P. 1987. Oral Literature of the Trio Indians of Suri- nam. Dordrecht/Providence: Foris Publications.

MORTON, J. 1979. Conceptions of Fertility and Mortality among the Waiwai Indians of Southern Guiana. Ph.D. Thesis, University of Oxford.

OVERING KAPLAN, J. 1981. "Review Article: Amazonian Anthropology". J ournal of Latin American Studies, 13:151-165.

REICHEL-DOLMATOFF, G. 1971. Amazonian Cosmos. The Sexual and Religious Symbolism of the Tukano Indians. Chicago: University of Chicago Press.

RIVIĖRE, P. 1969. Marriage among the Trio. A Principle of Social Organisation. Oxford: Clarendon Press.

. 1971. "The Political Structure of the Trio Indians as M anifested in a System of Ceremonial Dialogue". In: T. O. Beideman (ed.), The TransIation of Culture. London: Tavistock. pp. 293-311.

TAYLOR, A.-C. 1993. "Remembering to Forget: Identity, Mourning and Memory among the J ivaro". Man, 28: 653-678.

VIVEIROS DE CASTRO, E. 1996a. “Images of Nature and Society in Amazonian Ethnology". Annual Review of Anthropology, 25:179-200. . 1996b. "Os Pronomes Cosmológicos e o Perspectivismo Ameríndio". Mana, 2(2):115-144. 


\section{Resumo}

Este artigo se baseia no argumento de Philippe Descola de que há uma homologia entre a maneira como as pessoas tratam a natureza e a maneira como se tratam entre si. Ele contrasta os povos jívaro e tukano - o primeiro organizando a relação em termos de predação, o último em termos de reciprocidade. É introduzido um terceiro elemento na comparação: a região das Guianas, onde se encontraria, segundo a hipótese aqui formulada, um certo grau de autocontenção do grupo social e de isolamento diante da natureza. Isto de fato é verdade, mas é também possível identificar, dependendo dos dados e do contexto, relações predatórias e recíprocas com a natureza ou o exterior. É então sugerido que este seja não apenas o caso das Guianas, mas da A mazônia de um modo geral.

Palavras-chave Amazônia, Guianas, Predação, Reciprocidade, Animismo

\section{Abstract}

This paper is based on Descola's argument that there is an homology between the way in which people treat nature and the way in which they treat each other. He contrasts the J ivaroan peoples with the Tukanoans; the former organizing the relationship in terms of predation, the latter reciprocity. A third contrast in the form of the Guiana region is introduced and it is hypothesized that a degree of self-containment, an isolation from nature, will be found there. In fact it is, but it also possible to identify, depending on data and context, predatory and reciprocal relationships with nature or the outside. It is suggested that this is likely to be generally the case.

Key w ords Amazonia, Guiana, Predation, Reciprocity, Animism 